\title{
Quality of Governance and Ethical Public Service Delivery (PSD) in Developing Countries
}

\author{
Jean-Claude Garcia-Zamor ${ }^{1}$ \\ ${ }^{1}$ Department of Public Administration, Florida International University, Miami, Florida, USA \\ Correspondence: Jean-Claude Garcia-Zamor, Ph.D., Professor, Department of Public Administration, Florida \\ International University, Miami, Florida 33199, USA. Tel: 305-348-0428
}

Received: June 18, 2015

Accepted: July 10, 2015

Online Published: August 5, 2015

doi: $10.5430 /$ jms.v6n3p28

URL: http://dx.doi.org/10.5430/jms.v6n3p28

\begin{abstract}
The article reviews different conflicting values that often put donor organizations on a collision course with the recipient countries. It focuses on public values and relates the topic to the broader value framework of quality of governance. It also discusses some of the problems that exist in several developing countries such as the absence of established acceptable ethical norms and when there are, they are ignored with impunity. It looks at the role of rampant poverty in breeding corruption, and the fact that public service institutions are weak. The cases of Nigeria (still a developing nation) and South Africa (an emerging economy that might join the BRIC group) are briefly reviewed. They present two insightful case studies to analyze the clash between public values and quality of governance in PSD with the two countries adopting different strategies. Although the article focuses on public service delivery (PSD), it also looks at public values in the broader value framework of quality of governance as one of the major obstacle for an efficient cross-national public service delivery. The ethical and cultural dimensions of Alternative Service Delivery are discussed both at global, national and local levels.
\end{abstract}

Keywords: governance, public values, ethics, globalization

\section{Public Service Delivery (PSD)}

Government has, since its primitive conceptualization, evolved to mean many things and play different roles dependent on each government's constituency or key influencers. A post-war trend for government has been the development of government-centered public service. The rise of government's responsibility to the people in the form of providing what is viewed as necessary services has been a central focus in the field of Public Administration. The role of government has been in direct correlation with a shift in public values, occurring internationally and nationally, many times driven by nations' progress towards development.

PSD is an important dimension of development administration that involves the government, private, and third sectors. Public services include health, education, employment assistance, infrastructure, and agriculture to name a few. Populations across the globe often demand that their governments deliver public goods to them; however, in some instances, particularly when it concerns extreme poverty, these demands go unmet by governments. The third sector consisting of nongovernmental organizations (NGOs) and other nonprofits fill the gap where governments have not effectively delivered public goods.

This article reviews the global partnerships between NGOs, host governments, and external donors and discusses the different modalities of PSD. The debated concepts of "public values" and "quality of governance" are defined, and conflicting values between donor and recipient countries are explored. It also discusses poverty and corruption as impediments to successful PSD in developing countries. The cultural and ethical dimensions of Alternative Service Delivery (ASD) are discussed at the global, national, and local levels. There are several stakeholders and competing interest involved in PSD and the success of NGOs often depends on how well these interested parties can control the programs they are implementing.

\section{Public Values and Quality of Governance}

Public values and the framework of quality of governance are important concepts used by scholars and practitioners alike when analyzing international assistance programs. Public values are terms that are defined differently by scholars and ones that vary depending upon national contexts. This is why the definition of values among 
cross-national entities varies widely. However, there are certain principles that should be universal in order to properly develop the building blocks of good institutions. The concepts of "governance" and "good governance" are also hotly debated within academic circles. This article defines what public values and quality of governance are in order to demonstrate how these concepts are an obstacle to efficient cross-national PSD.

\subsection{Public Values}

To identify and list values that are applicable for all stages of government or human organizations is an elusive, if not impossible, feat. Values vary from person to person, and therefore become more complex to identify for larger groups. Under their governments, societies have developed social values, which dictate their behavior and give place to the activities by level of importance. Samaratunge and Wijewardena (2009) argue that "trust and legitimacy should be the center of public values", even if the remaining factors vary through time and spatial dynamic change. From a materialistic view, public values are what drive consumers, in this case society, to demand certain goods and services from providers.

Who the providers are has also changed through time, due in part to changing values. When people once looked purely at their government to provide certain services, new providers have emerged which sought to fill the gaps or share the load of governments in providing public services. Non-profit organizations, non-governmental organizations, multinational organizations, contracted corporations, and even the fracturing of government into state or local governments, have all become major players in the realm of public service delivery.

Previous literature stresses the importance of public involvement in shaping cultural values. Andersen, Jorgensen, Kjeldsen, Pedersen and Vrangbeak (2013), consider that values "are the basic building blocks of the public sector" which, when coupled with motivation, can lead people and therefore organizations, to act apart from self-interest or the interests of said organization. This motivation, they argue, is due to the ability to feel identified with another group or person's plight. Self-sacrifice, empathy, and this feeling of identification lead others to action, as "a value with no effect on behavior is not a value".

The nature and amount of international aid provided by donor countries is largely dependent upon how the population of the donor country values such assistance. Public values are rooted in society and culture is ultimately determined by individual members of a state. The ambiguous nature of the concept public value permeates the debate on what the primary purpose is for a public sector organization. Public agencies are attempting to serve some public purpose; therefore, the question becomes what is an agency trying to achieve and how is the purpose determined? In answering this question, Hughes (2012) states "...agencies do things that the public wants, that the public values, and through mechanisms that have existed for a long time" (p. 222). Moreover, Moore (1995) argues that public agencies should seek to create "public value", similar to private value created in the private sector, by utilizing public managers as strategists, as opposed to only technicians, as they seek to create public value. Functioning as strategists, public managers seek to define and produce public value, they seek to innovate and lead the evolution of what public agencies do and how they do it (Hughes, 2012). Moore and Hughes develop a useful framework of public values, which define public values to be what a society or culture values, such as accountability, human dignity, common good, free market economies, and effectiveness. Ultimately, these values come into conflict between donors, host governments, and NGOs. The conflict between values placed on free market economies versus state controlled economies is discussed in the article.

\subsection{Quality of Governance}

The importance of community involvement in the creation of public values is highly emphasized. Proper representation of the people is key, as combining public values with motivation leads to the development of systems of governance. This is why, if values differ, so will governance systems differ. Four basic systems of governance are recognized. A hierarchical mode of governance stresses loyalty and neutrality; with a clear top-to-bottom flow of power. A clan type of governance separates groups by specialization, and both needs and values professionalism. A network-centered governance style values balance and fairness; joining several players through compromise. Finally, the market style of governance values efficiency and individuality, giving governance a more materialistic tone that has certainly been a product of current times (Andersen, Jorgensen, Kjeldsen, Pedersen and Vrangbeak, 2013).

These basic levels of governance are a fairly simplistic way of understanding the interconnectivity and diversity in the modes of governance. Just as individuals and communities represent a plethora of values being joined together for a common good, or at least for the good of the majority, so do different modes of governance find themselves existing together. Quite often these relationships provide conflict between modes of governance. Values clash and 
ethical issues are then questioned, such as the extent to which organizations are responsible for certain services, or whether what were once considered public values can now be turned to the private realm in the name of efficiency.

The concept of hybrid governance comes into the forefront, as "cross-sectional partnerships among public, nonprofit, and for-profit organizations" begin to share in providing services to communities, as seen recently in the United States (Chen, 2008). There is a focus on the ability that inter-organizational systems have in providing functional networks to be able to share in resources and responsibilities for providing public services. The key value in these new hybrid forms of governance is trust. Organizations, big and small, must be willing to discard pride and autonomy, yet be able to preserve their individuality which allows them to work efficiently together in tackling certain perceived public problems. An imperative step in forming collaborations is identifying preferred outcomes for such collaborations, and shifting importance to the steps conducive to such outcomes. Chen (2008) stresses that collaboration should be process-oriented and process-determined by desired outcomes.

The concepts of 'governance' and 'good governance' are debated by social scientists that use varying operational definitions of the words. Bovaird and Loffler (2003) argue that the definition of governance must be context specific resulting in each unique country and set of interested parties arriving at different definitions of governance. They define governance as "the ways in which stakeholders interact with each other in order to influence the outcomes of public policies" (p. 316). They go on to state that good governance is "the negotiation by all the stakeholders in an issue (or area) of improved public policy outcomes and agreed governance principles, which are both implemented and regularly evaluated by all stakeholders" (Ibid.). These definitions provide an operational framework to analyze the role quality of governance plays in PSD.

The indicators for measuring and evaluating the quality of governance have proven challenging for social scientists to define and agree upon. Bovaird and Loffler (2003) build a two component framework to measure the quality of governance. One component is examining improvements in public policy outcomes; however, it is difficult to measure policy outcomes, as it requires inter-agency collaboration as well as sharing data, which is not often popular within agencies. Scholars and practitioners evaluate policy outcomes in terms of how the policies have improved the lives of the people they are targeting. For example, income levels and working conditions are evaluated as opposed to the performance of specific economic development programs to determine the efficacy of a policy (Bovaird \& Loffler, 2003). Moreover, improvements in health status, percentage of people living within a certain distance of a park, people feeling less pain, and lower levels of obesity, for example, are looked at to measure quality of life improvements (Ibid.). According to the two authors "...the best known 'quality of life' measurement project is the Human Development Index (HDI) of the United Nations" (p. 320). The HDI ranks countries by the quality of life of their citizens rather than using strictly economic indicators.

The second component used by Bovaird and Loffler to measure quality of governance is looking at how well agencies perform against public governance principles and processes. They list ten principles and processes that frequently appear in the literature as indicators including "citizen engagement, transparency, accountability, the equalities agenda and social inclusion, ethical and honest behavior, fair procedures and due process, ability to compete in a global environment, ability to work effectively in partnership, sustainability, and respect for the rule of law" (p. 322). Even so, scholars and practitioners assign different meanings and importance to these terms depending on the context and interested parties involved in the debate. According to Bovaird and Loffler, the most widely known governance index is the corruption perceptions index (CPI) of Transparency International. This poll reflects the views of business people and country analysts in ranking the level of corruption of countries included in the index. The quality of governance of developing countries implementing structural adjustment programs (SAPs) and the value the recipient states place on free market policies are discussed in the article.

\section{Modalities for Public Service Delivery}

Public Service Delivery (PSD) has diverse modalities across different levels and sectors. Aid can be provided through bilateral and multilateral avenues and can target specific sectors such as the agriculture and health spaces. The value the public places on providing and receiving aid directly affects the form international aid takes. Moreover, the quality of governance of host governments and recipient NGOs directly impacts the efficacy and perception of international assistance. Donor and recipient countries can have conflicting values that put them at odds with each other as international assistance programs are negotiated and implemented.

In the case of the United States, Hoy (1998) states that international aid is criticized by elected officials and foreign aid is constantly facing the threat of elimination from Congress and a disenchanted public. Moreover, wealthy countries around the world continue to drop the level of assistance they provide, following the example of the United States (Ibid.). Although international aid may decrease globally, the world still has significant aid needs in the areas 
of fighting malnutrition and extreme poverty. What is more, international assistance makes up a relatively small percentage of fiscal budgets globally, less than $1 \%$ in the case of the United States; therefore, the reason aid is being reduced is not a question of unmet needs or economics (Hoy, 1998). The reduction in aid provided by the United States comes from the American people's desire to have domestic needs prioritized before any international aid is provided. Hoy points to the isolationist argument that posits the United States should focus on remedying its domestic problems before it goes abroad to attempt to solve other countries problems as the explanation for decreasing aid. However, he argues that the isolationist argument is weak in the era of globalization, where technology and private capital flows bring the third world closer to first world nations. Whether it is infectious diseases affecting either developed and undeveloped countries alike, or refugees fleeing conflict-torn regions, wealthy nations no longer live in isolation, at a distance from the third world. The recent Ebola epidemic that started in Africa and quickly reached some industrialized countries illustrates this point. The question then becomes, are there international aid programs that effectively support development?

To answer the question of whether international aid programs are effective or not, various modes of PSD will be reviewed. International assistance is provided through diverse modalities, at different levels and in different sectors. This aid takes form in project aid, program aid, technical assistance, food aid, emergency or humanitarian assistance, and military aid (Hoy, 1998). Project aid, assistance with a specific goal in mind such as the building of a road, is assistance that both donor and recipient countries are amenable to. Donor countries can readily observe the fruits of the aid at project completion while the recipient country can leverage the public works project into political capital. Program aid is a general form of aid that places many terms and conditions on the recipient country. This type of aid was preferred during the debt crisis and will be elaborated on in this article. Technical assistance takes the form of donor countries contributing experts or equipment to the recipient country with the goal of training local populations in development strategies. This aid is often used in the agriculture and health sectors, however, there are many questions as to who really benefits from this aid. Hoy states, "The fact that 90 percent of the $\$ 12$ billion spent on technical assistance each year goes to foreign expertise, despite the availability of national experts who need jobs, provides a disturbing answer to the question" (p. 3). Food aid is also controversial and takes form in providing dairy products, cereals, etc. to support countries facing emergency food scenarios. The least controversial among international assistance modes is humanitarian, or emergency aid, which is provided to countries facing life-threatening disasters, such as earthquakes or tsunamis. Military aid, which provides assistance in strengthening the military of the recipient country, is often not considered a true form of aid because it does not contribute to economic development in the recipient country. The "strings" attached to program aid can bring conflicting values and quality of governance into sharp focus, as was the case in debt relief programs in the 1980s.

International aid is delivered to recipient countries by donor countries using three primary modes of delivery: bilateral, multilateral, and nongovernmental organization delivery. Bilateral aid is a direct transfer between the donating and receiving governments. Multilateral aid is provided through international organizations such as the World Bank or the United Nations. Private, nongovernmental organizations deliver aid to assist countries in fighting malnutrition and poverty. Multilateral aid brings into focus institutional weaknesses of countries implementing programs provided by the International Monetary Fund (IMF) for example. The IMF provides directives on economic reforms in order for the recipient country to receive debt relief, however, corruption and institutional weaknesses often prevent the effective implementation of these aid programs.

\section{Corruption and PSD Abroad}

Some traditional public service delivery methods have correctly focused on lean, efficient and facilitative government, as well as a strong focus on a high performing civil service (Hassan, 2011). The level and sectors of delivery vary widely among different countries, as do the historical norms and culturally influential mores. A field of increasing involvement in PSD is information technology. Governments are increasingly relying on public-private partnerships with information technology firms to "design, produce and operate effective and efficient public services" (Prefontaine, 2000). This trend has only increased in the new millennium with public-private partnerships becoming the norm, as opposed to the exceptions. But ethical concerns may arise when a private entity benefits mightily and the public only benefits marginally. This is often the case when international aid agencies are forced to deal with often unscrupulous leaders in delivering public services to the needy. In the process of delivery, some of the aid may be siphoned off through corruptive means. The private entity delivering the aid might find itself in a position where only a small portion of intended aid actually reaches those whom it was supposed to reach.

Differences among different levels and in different sectors are more nuanced at the international level where the level of governmental centralization is very high, as opposed to industrialized countries where aid to the needy is more 
fractured and offered by a myriad of public, private and public-private entities or partnerships. Regardless of these factors, the grand necessity is to have a strong, viable foundation that facilitates aid workers to effectively deliver public services.

There are many conflicting values that can stand in the way of successful implementation of PSD in developing countries. While most governments and non-governmental organizations are well intentioned to provide aid to the poor, often times the systems do not allow for success. For example, since aid is usually brokered through governments, considerable aid can often be siphoned off by corrupt officials, either through outright embezzlement or by diverting aid disproportionately to government employees and/or the well-connected elite. This aid can also be used to entrench inept, corrupt, or dictatorial power within the receiving nation. This is likely never the intention of NGOs and governments providing aid, but the reality is what happens often and regularly. Aid to a dictatorial or authoritarian nation potentially allows the groups in power to punish his enemies and reward his cronies.

As already mentioned, corruption can become a major concern when providing aid to developing nations. Research has focused on several indicators and confounding variables dealing with corruption and foreign aid. It is impossible for aid givers to expect their projects to be free from a nation's corruption. There is no evidence to sustain the belief that aid-funded projects can be completely separated from a nation's corruption. The idea that poverty is the driving cause for corruption is not sound. As Kaufmann (2005) argues, evidence shows "better governance as being the cause of higher economic growth" an opposite causal relationship from mainstream understanding of poverty being the driving force for corruption.

The fact that corruption exists in developing countries cannot be a factor that disqualifies them from receiving aid for generally accepted development and humanitarian projects. However, this dynamic between aid and corruption leads organizations to search for ways to respond to this troubling relationship. Here, two conflicting views arise. First, aid can be given only when programs are tied to them, which may improve governance, "reduce corruption, improve fiscal accountability" and develop the civil service (Knack, 2001). Knack presents data from 2000 showing the World Bank as supporting more than 600 anticorruption and governance initiatives. Second, is the idea proposed by Kaufmann (2005), where he poses that anti-corruption programs actually serve to neglect other important government reforms that can prove more beneficial in the long-run for developing countries.

Proposed methods for reducing corruption in developing nations vary and include a range of sectors which must be reformed. The private sector plays a big part in corruption. For example, some international corporations take advantage of weak governments by working with corrupt leaders for mutual benefit. This calls for a push for transparency and greater representation and participation of citizens through an increase in rights equality for minority groups and an increase in transparency and freedom of speech (Kaufmann, 2005).

Aid could be focused on developing technological tools, aiding in transparency and better governance. Knack (2001) refers to the World Bank's Governance Knowledge-Sharing Program, where anyone with internet access could benefit from free resources regarding public sector reform, providing nations' own governments with the knowledge to make informed decisions about which reforms to implement.

\subsection{Ethics, Culture, and PSD in Nigeria}

Nigeria presents an insightful case study to analyze the clash between public values and quality of governance in PSD. Nigeria is one of the poorest countries in the world but is also endowed with profitable oil reserves making it a top oil exporting country. Unfortunately, in large part the result of rampant corruption, oil rents have had marginal impact on reducing poverty in the African nation. The overwhelming majority of government revenues come from the sale of oil; however, this industry concentration, along with failing to diversify the economy, has led politicians and their constituents to fraudulently enrich themselves and their broader ethnic groups. Political elites in Nigeria have attempted but failed to reduce poverty and promote development in the poorest areas of the country.

Nigeria has made several attempts to reduce poverty through government initiatives such as the creation of the Department of Food, Roads, and Rural Infrastructure (DFFRI), which had a goal of opening the rural areas to development, the creation of the National Directorate of Employment (NDE), with the objective of tackling the problem of mass unemployment, and many other national development programs (Elumilade and Asaolu, 2006). However, these programs are often abandoned, or are ineffective, as a result of individuals hijacking the programs for personal gain. Elumilade and Asaolu (2006) posit that personal rivalries among political elites, rather than impersonal institutions, are what shape the outcomes of development programs in Nigeria. In other words, weak institutions in Nigeria give way to the personal rule resulting in the usurping of political institutions. Moreover, development programs fail because political elites assume they know what poverty is and how to relive it when, in 
reality, it is the impoverished person that understands poverty and how to alleviate it. Pursuant to this argument, Nigerian officials do not incorporate the perspective of poor people and are doomed to failure before a development program is devised. The cultural dimension of patrimonialism, where political leaders trade political favors for loyalty among their respective ethnic groups, is in large part responsible for the parent-child dynamic of development administration in Nigeria and is in part responsible for the corruption associated with diverting government revenues to personal ethic groups. This cultural aspect of Nigerian society leads to significant levels of corruption where it is acceptable for the ethnic group in power to care for their own and exclude other groups.

On the surface, Nigeria's formidable oil reserves should prove to be an asset in reducing poverty; however, political elites, including some Presidents of Nigeria, are guilty of embezzling money to fund personal accounts as well as engaging in favor-for-favor politics. This culture of corruption seeps into the PSD space with political elites siphoning off money to enrich themselves and their constituents. With rampant poverty, it is easy for an elected official to take bags of rice to his or her impoverished district in order to shore up support and votes, and the cycle of corruption continues with each successive regime and legislature. In the final analysis, Nigeria has high levels of poverty in spite of the abundant natural and human resources. Elumilade and Asaolu (2006) state that "what is found is the poor management of these resources because of bad government, corruption, and huge external debt" (p. 76). Institutional weakness and rampant poverty provide the space for officials to engage in corruption unimpeded.

\subsection{Ethics, Culture, and PSD in South Africa}

Mubangizi and Gray's (2011) look into South Africa's progress from apartheid into a democratic developing nation can shed light into local methods for improving upon governance and public service delivery of a foreign nation. Establishing a fees-for-service delivery system, South Africa's government has had to take steps into educating the population on this seemingly foreign concept. A lack of resources, skilled public sector, and corruption called for a greater relationship between the public and private sector, in the form of contracts for services such as water resources and emergency services. Reform sought to change public mentally into that of a consumer/provider relationship, where effective communication between the local community and private providers could lead to beneficial public service delivery exchange.

South Africa introduced both new and traditional methods of community involvement, to ensure that citizens are educated in the importance of government participation, and to change negative perceptions towards fees-for-service style of delivery. The new method of involvement is referred to as an Integrated Development Plan. IDPs allow for a shared space where municipalities can identify strategies and plans for achieving development and what this means to the community. The traditional method is that of Izimbizo, referencing traditional meetings led by local leadership, where government officials hold meetings in certain communities with the intention of providing a forum for open communication between leaders and citizens regarding service delivery and development.

Although not perfect, the example of South Africa serves to highlight many of the public service delivery themes and trends. It is a nation where a hybrid form of governance has begun to develop. Citizens enjoy services from the government, while a lack of resources and skilled administrators is answered by the contracting of private sector entities and other organizations. Cultural idiosyncrasies are addressed through modes of community participation. Continued education of both citizens and public officials has led to a wider reach of public services, expanding to the generally excluded poor communities and traditional groups, on the international stage. This example shows that some kind of effective PSD is possible in developing countries, and gives insight into future proposed initiatives.

\section{Globalization, Public Values and Governance}

Globalization has also been a major player in the shift of values, and therefore governance. Diversity has been able to increase due to the process of globalization, as new culture-groups begin overtaking traditional majority groups, as it is with the Hispanic population in the United States. This cultural diversity has created a great need for more culturally sensitive public administration methods. Rice argues that there is a need for "culturally appropriate and culturally responsive public service programs and public services in the post-modern era of diversity" (2007). He elaborates that a new method of public service delivery must take into account the difference in values and norms different cultures bring. Culture "shapes how individuals see and respond to the world and community around them" (Ibid).

Governance is an essential element in cross-national public service delivery. In order to have good governance, a governmental entity must abide by some critical elements. A fair legal system is essential in creating and maintaining good institutions. Ethics of such a system must be of the highest quality and must be duly enforced. Otherwise, the corrupt entities will merely use the rules against the opposition. Another crucial element to good governance and one 
that is difficult to achieve is citizen participation. Since many developing nations lack good institutions, they likely will also lack good transportation and communications infrastructure. Because of the high governmental centralization in many developing nations, decisions that affect local citizens are made by remote governmental agencies that are far from the people, both conceptually and geographically. This creates a large separation between the government and the governed, which can result to an undesirable phenomenon known as social exclusion. Those citizens that are socially excluded find themselves confined to the fringes of society (UNDP, 2011).

M. F. Rice states that the field of Public Administration has failed to recognize and incorporate the importance of cultural competency into its realm of study, and has therefore left public servants having to search other professional fields for tools in how to properly respond to cultural challenges and therefore the needed changes in public service delivery. Public Administration has "traditionally...supported culture blind services and programs...a focus on cultural differences/cultural variations does not fit the traditional neutrality/equality principles" (Rice, 2007). Because of this, Rice argues that many times public service delivery has provided assistance and services that hinder minority groups.

There has been a shift in the US Government striving for cultural competency, such as by providing and promoting services in foreign languages, which has proven to improve on the effectiveness of public service delivery. An illustration of this is the case of the City of Miami, Florida, where numerous government rules are published in Spanish and Creole because of the large number of Spanish-speakers (mainly Cubans) and Creole-speakers (Haitians) in the community. By providing minority groups with resources in their own language, there is a decrease in the possibility for incorrect delivery, therefore driving down costs and the possible chance of liability. Governance needs to include methods for assessing cultural barriers, as well as the proper training for Public Administration professionals.

On the global scale, this push towards a more complex form of governance has also been referred to as Integrated Governance. Integrated Governance highlights the importance of developing a skilled cadre of public managers. Samaratunge and Wijewardena (2009) argue that for developing countries, new reforms focused on increasing governance and democracy in the public sector have suffered from a lack of experienced public workers. They point to the inability of public managers to have the capacity to deliver quality service in an efficient manner...due to the lack of a competent civil service.

Governance structures in developing nations must be formed through citizen participation with all levels of society participating through governmental processes in defining values and expectations. The shift towards civil and human rights has created an "emancipation of the masses", increasing the public's demand for rights and services to deliver on these notions (Samaratunge and Wijewardena, 2009). The repeated value of trust becomes the center of public service in developing nations as new governance systems seek to respond to these demands. The two co-authors argue that creating a right government structure is one of the key conditions to poverty reduction, as high levels of poverty remain one of the priorities for developing nations, a notion shared by the international community.

There is a push for collaboration between different sectors, local and international, private and public, towards achieving development goals. Where we once saw a strong, independent government, we now have begun to experience a blurring of lines between the public and private sectors. There is a shift in public perception where other sectors also have much to contribute to the policy making and implementation processes, as citizens claim autonomy in determining what and how services are delivered (Ibid.). Samaratunge and Wijerwardena go as far as to suggest that research implies that developing nations must focus on creating the right governance environment in order to decrease poverty.

In relation to external aid being provided to developing nations, there is a trend for prescribing certain governance and economic restructuring guidelines as a method for protecting funds and assuring that fund goals are met. Knack (2001) writes that conditioning aid on policy and governance reform is largely ineffective. Furthermore, he states that aid can keep both good and bad governments alive, funding governments to do nothing or funding positive reform measures. He gives the example of South Korea and Taiwan, both being countries that experienced a shift towards real development only once international aid ended. The country of Somalia has experienced the opposite of what aid aims to achieve, only exacerbating violence and civil war, as leading groups fight to control aid resources.

Again, the importance of community participation in the development of values and governance is highlighted because aid can weaken governmental accountability by retarding the development of a healthy civil society. In other words, societies must run through a natural course of governance where history helps develop the values and processes needed for countries to survive and function in an accountable, transparent way (Knack, 2001). Whereas for developed nations there was a natural building of trust first by monarchs and then on by democratic leadership 
through taxation for services, foreign aid makes makeshift governments responsible to the donors rather than their constituents.

External aid is prone to dictate which institutions are valuable and how they should function. Many times these institutions are built and remain dependent on aid, finding as aid runs out that there are not enough skilled leaders, or funds, to lead them through the future. New foreign-backed projects can disrupt the improvement of the service workforce, through competition for skilled talent between organizations and governments. Despite this situation, many developing countries' bureaucrats were the most vocal supporters of the dependency theory (Garcia-Zamor, 2006). Countries may also experience a weakening or hindrance to development of the private sector, as governments can take the funds meant for the public sector, which is now funded by foreign aid, and use them to subsidize corporations and industries.

\section{Alternative Service Delivery}

Alternative service delivery (ASD) is provided by non-governmental organizations (NGOs) and other non-profits. NGOs provide social services such as education, health, and housing, through bilateral and multilateral partnerships between the respective NGOs and external donors (Henderson, 2002). These public goods are provided to the population through the NGOs instead of being delivered by the host government. Scholars often distinguish between Northern Donors and NGOs of the world and Southern Donors and NGOs. Northern donors, mostly wealthy donors, often choose projects to fund based on their own objectives and values, and they implement their own rules to govern the project. External donors try to coordinate efforts with recipient NGOs; however, this often results in a top down management approach with the donor providing directives to the recipient. NGOs comprise the third sector, with the government as first sector and private enterprises as the second sector.

As developmental aid moves toward an alternative delivery system, we must account for the seen and unseen effects of PSD of developmental aid. It is imperative that development aid workers and agencies recognize and account for successes as well as failures. For example, the success stories of foreign aid to "South Korea, Taiwan, Botswana, Indonesia, Mozambique and Tanzania" must not be the only considerations. We must also account for, and learn valuable lessons, from the failures in "Guinea-Bissau, Somalia, Gambia, Mali, Rwanda, Nicaragua, Burundi, Guyana, Zambia, the Central African Republic, Senegal, Suriname, Chad, Niger, Togo and so on" (Easterly \& Radelet, 2006).

Accountability is oftentimes lacking. In the case of foreign aid, some of the problems can be associated with simply trying to do too much without proper accountability measures in place. An adequate Alternative Service Delivery (ASD) mechanism can alleviate this situation by expanding the considerations of public service delivery. ASD has been defined by Ford and Zussman as a creative and dynamic process of public sector restructuring that improves the delivery of services to clients by sharing governance functions with individuals, community groups and other government entities (World Bank, 2002). According to the World Bank, this system incorporates privatization as well as reorganization and reengineering of mainstream government. Accountability within this model is central to its success. It fills in some of the blanks within the traditional public service delivery model through its focus on several questions. Among them is whether the program continues to serve a public interest, whether there is a legitimate and necessary role for the government, does the implementing agency have the jurisdiction to take actions, should this program be provided by government, the private or non-profit sectors and it also inquires whether the program is affordable within fiscal realities (Ibid.).

This ASD system goes much farther than the traditional PSD model and puts a much needed emphasis on need and accountability. Asking whether a government program should continue is unlike most government programs that exist in perpetuity, regardless of need or affordability. Another crucial point is whether there is a role for government to act in the first place. These are not the usual questions explored by congressional committees or elected officials in most capacities. These principles add crucial checks and balances to decision making that go farther in achieving good governance.

\subsection{Ethical and Cultural Dimensions of ASD}

Ethics have a significant influence on ASD at the global, national, and local levels. Many allegations of corruption and fraud have been leveled against NGOs across the globe. Gibelman and Gelman (2004) state that the wrongdoings of NGOs can be grouped into "six major categories of wrongdoing: personal life style enhancement, parallel enterprises, resource expansion opportunities, theft, mismanagement of resources, and support of activities and groups outside of the organization's purview" (p. 370). The board of directors of an NGO is the policy making body and the directors have a duty to act in the best interest of others; however, this fiduciary duty varies from country to country and even varies at the local jurisdiction level (Ibid.). The directors are responsible for ensuring the 
ethical integrity of their organizations; however, the proliferation of corruption in NGOs suggests a failure of governance.

There are cases of alleged abuse and wrong doing by NGOs at the global, national, and local levels. Many of these cases involve allegations of misappropriation of money, kickbacks, embezzlement, and bank fraud, which are commonly grouped under allegations of corruption. The case of the Iraqi oil-for-food-program scandal, where only a small amount of funds reached the beneficiaries, demonstrated a failure of governance at the global and national levels. The United Nations was accused of a multibillion-dollar fraud cover-up involving the Iraqi oil-for-food-program in this instance. Another incidence of corruption arose after the September 11 terrorist attacks in the United States of America (Gibelman \& Gelman, 2004). In the wake of the attacks, donors contributed to new founded charities that focused on caring for post-traumatic stress disorder and the practical needs of surviving victims. Allegations were made that funds donated to charities focusing on survivors of the attacks were funneled to terrorist organizations. Due to the international nature of the charity groups and the movement of money in the global banking system, the impact of these allegations was detrimental to the ability of these NGOs to deliver services. This scandal further illustrates that in a globalized economy, ethical concerns can penetrate through the global, national, and local levels.

In the wake of numerous national and global scandals, increased scrutiny and regulation of NGOs has become a public priority. The public has demanded more accountability from NGOs. New regulatory agencies, or "watchdog" agencies, have emerged to provide stricter oversight of NGOs and assist in the development of ethical and practice standards (Gibelman \& Gelman, 2004). Agencies such as the Better Business Wise Giving Alliance and the Philanthropy Foundation in the United States are newer groups which regulate NGOs. Moreover, the World Association of Non-Governmental Organizations created a Code of Ethics and Conduct which provide guidance to NGOs. These watchdog groups have proliferated globally with the Philippine Council for NGO Certification, for example, providing tax certifications to NGOs in the Philippines. Ethical concerns will continue to be a major concern as the world continues to improve the quality of life of mankind.

\section{Conclusion}

PSD is provided by NGOs, governments, and external donors working unilaterally, bilaterally, or multilaterally. Donors often pursue their own self-interests, mainly economic and political concerns, as they provide aid with rules and stipulations. Donors demand accountability, transparency, and specific policy prescriptions, which are often at odds with NGOs and host governments where corruption is rampant. Donor countries want results from the programs and attach rules to program aid packages. This can be seen in the debt crisis of the 1980s when Structural Adjustments Programs (SAPs) were provided by donor countries with stipulations that these countries were to privatize state owned enterprises and pursue free market policies. The developed world's insistence on neo-liberal policies often clashed with societies that previously pursued protectionist and isolationist policies.

SAPs are a classic example of how public values clash with quality of governance. The developed world values neoliberal, free market policies that emphasize privately owned enterprises, foreign direct investment, free floating currency, and prudent fiscal management. The effectiveness of free market policies depends largely on the quality of governance that oversees the economic programs. The causes of failure of some SAPs is hotly debated with theories of implementation failure debated along with theories that certain countries do not have the quality of governance needed to implement such programs, or their societies do not value neoliberal, free market policies.

A culture of corruption and mismanagement could be found in many countries that pursued Import Substitution Industrialization (ISI), such as Nigeria, where stakeholders engaged in embezzlement and poor business practices. Moreover, critics of neoliberal policies argue that they do not do enough to address poverty and the plight of poor people around the world. In the case of providing debt relief, the public value developed societies place on free market economies clashes with the value developing countries place on state controlled economies. Finally, the quality of governance comes into play with donor countries providing directives for program management while the recipient countries struggle to implement the reforms due to rampant corruption and institutional weakness that stifles development efforts.

Jared Diamond argues that perhaps most economists regard good institutions overwhelmingly as the most important explanation for a nation's success (Diamond, 1999). We can deduce that these institutions would fare much better and be more accountable to their people if they were to adopt the principles within the alternative service delivery (ASD) mechanism. These concepts will advance the foundational principles that will build good institutions and will then result in improving the public sector. It could also be argued that without the rule of law, enforcement of 
contracts, protection of private property rights, lack of corruption, openness to trade and to the flow of capital, it will be very difficult to break the cycle of poverty and lack of investments that plague developing nations.

\section{References}

Andersen, L. B., Jørgensen, T. B., Kjeldsen, A. M., Pedersen, L. H., \& Vrangbæk, K. (2013). Public Values and Public Service Motivation Conceptual and Empirical Relationships. The American Review of Public Administration, 43(3), 292-311.

Bovaird, T., \& Löffler, E. (2003). Evaluating the quality of public governance: indicators, models and methodologies. International Review of Administrative Sciences, 69, 313-328.

Chen, B. (2008). Assesing interorganizational networks for public service delivery: A process-perceived effectiveness framework. Public Performance \& Management Review, 31(3), 348-363.

Diamond, J. (1999). Guns, Germs, and Steel: The Fates of Human Societies. New York: W.W. Norton \& Company.

Easterley, W., \& Radelet, S. (2006, December 1). The Effectiveness of Foreign Aid. Council on Foreign Relations.

Elumilade, D. O., \& Asaolu, T. O. (2006). Appraising the institutional framework for poverty alleviation programmes in Nigeria. International Research Journal of Finance and Economics, 3, 66-77.

Garcia-Zamor, J. C. (2006). Neoteric Theories for Development Administration in the New World Order. In E. E. Otenyo and N. S. Lind (Eds.), Comparative Public Administration: The Essential Readings (pp. 297-320). Oxford, England: JAI Press Publications.

Gibelman, M., \& Gelman, S. R. (2004). A loss of credibility: Patterns of wrongdoing among nongovernmental organizations. Voluntas, 15(4), 355-381.

Hassan, Tan Sri Mohd Sidek. (2011). Public Service Delivery. ETP Annual Report.

Henderson, K. (2002). Alternative service delivery in developing countries: NGOs and other non-profits in urban areas. Public Organization Review, 2(2), 99.

Hoy, P. (1998). Players and issues in international aid. West Hartford, CT: Kumarian Press.

Hughes, O. E. (2012). Public management \& administration ( $4^{\text {th }}$ ed.). New York, NY: Palgrave Macmillan.

Kaufmann, D. (2005). Myths and realities of governance and corruption. Available at SSRN 829244.

Knack, S. (2001). Aid dependence and the quality of governance: cross-country empirical tests. Southern Economic Journal, 310-329.

Moore, M. (1995). Creating public value: strategic management in government. Cambridge, MA: Harvard University Press.

Mubangizi, B. C., \& Gray, M. (2011). Putting the 'public'into public service delivery for social welfare in South Africa. International Journal of Social Welfare, 20(2), 212-219.

Prefontaine, L., Ricard, L., Sicotte, H., Turcotte, D., \& Dawes, S. (2000). New Models of Collaboration for Public Service Delivery Worldwide Trends. Retrieved February 22, 2015 from http://www.ctg.albany.edu/publications/reports/new_models_wp/new_models_wp.pdf

Rice, M. F. (2007). A post-modern cultural competency framework for public administration and public service delivery. International Journal of Public Sector Management, 20(7), 622-637.

Samaratunge, R., \& Wijewardena, N. (2009). The changing nature of public values in developing countries. Intl Journal of Public Administration, 32(3-4), 313-327.

United Nations Development Programme. (2011). Summary of Towards Inclusive Societies.

World Bank. (2002). Alternative Service Delivery Mechanism. Public Sector and Governance. 